\title{
The Effects of Outdoor Source on Pollution Characteristics and Dynamic Changes of Particulate Matter in an Office
}

\author{
Guozhong Zheng (D), Yuzhen Lu, Yajing Wang, Zhengzheng Zhao, Ke Li, and \\ Xutao Zhang \\ School of Energy Power and Mechanical Engineering, North China Electric Power University, Baoding 071003, China \\ Correspondence should be addressed to Guozhong Zheng; ansystem@126.com
}

Received 4 July 2018; Revised 24 September 2018; Accepted 18 October 2018; Published 28 November 2018

Academic Editor: Dong-Sheng Jeng

Copyright ( 2018 Guozhong Zheng et al. This is an open access article distributed under the Creative Commons Attribution License, which permits unrestricted use, distribution, and reproduction in any medium, provided the original work is properly cited.

\begin{abstract}
The indoor air quality has a direct impact on human health. Particulate matter is one of the important factors affecting the indoor air quality. The paper selects an office as the study object and studies the pollution characteristics and dynamic changes of indoor particulate matter in different outdoor pollution levels. The mass concentration of outdoor PM10 is used as the evaluation basis of the outdoor pollution level. The outdoor PM10 concentration levels are divided into the range of 200-300, 300-400, 400-500, $500-600,600-700 \mu \mathrm{g} \cdot \mathrm{m}^{-3}$, individually. Firstly, the change characteristics of the mass concentration and the number concentration of the particulate matter in the five outdoor conditions are analyzed. Secondly, the maximum increase values and the maximum increase rates of the mass concentrations of different particle sizes in the five conditions are compared. Then, the penetration factors of the particulates in different sizes are compared among the five conditions. Finally, the correlation between indoor particulate matter and outdoor particulate matter is studied. The study results show that the effect of outdoor infiltration has a great influence on the indoor PM1 mass concentration, and the penetrating factors of the particulate matter between $0.3 \mu \mathrm{m}$ and $0.5 \mu \mathrm{m}$ are higher than 0.6 ; their permeability is the most obvious.
\end{abstract}

\section{Introduction}

With the rapid development of economy and the continuous improvement of living standards, people's requirements for indoor environment are not only confined to indoor thermal comfort but also placed on the indoor particle pollution, namely, indoor air quality. According to the relevant data, a majority of people spend $70 \sim 90 \%$ of their time indoors, especially for the elderly people and the disabled man [1-3]. Therefore, indoor air quality is directly related to the health of a human body $[4,5]$. At present, indoor air quality has become an increasing concern topic in architecture, medical hygiene, building environment, real estate, etc. [6]. It is also a research frontier of modern architectural science.

Particulate matter is one of the primary pollutants in indoor pollution [7]. It is an important index to evaluate the indoor air quality. The size of indoor particles is usually expressed by aerodynamic diameter. A particle whose dynamics diameter is less than or equal to $100 \mu \mathrm{m}$ is called a total suspended particle, a particle whose dynamics diameter is less than or equal to $10 \mu \mathrm{m}$ is called an inhalable particle (PM10), a particle whose dynamics diameter is less than or equal to $2.5 \mu \mathrm{m}$ is called a fine particle (PM2.5), and a particle whose dynamics diameter is less than or equal to $1.0 \mu \mathrm{m}$ is PM1 [8]. Particulate matter, especially PM2.5, which contains a variety of harmful substances, is the carrier of microbial survival. As PM2.5 can enter the deeper part of a human body, it causes great harm to human health [9].

Researches on the relationship between indoor and outdoor particulate matter concentrations show that the mass concentration of the particles entering the indoor environment is in the same order of magnitude as the mass concentration of the outdoor atmospheric particles [10-12]. And the particles from the outdoor air are more harmful to the human body $[9,13]$. Thus, the impact of outdoor pollution on indoor particulate matter must be considered. The 
outdoor particles enter the room through the air infiltration via doors and windows, the fresh air of natural ventilation, and personnel entering, and they will affect the concentration and pollution characteristics of indoor particulate matter. The state of indoor particulate matter is a dynamic process. The changes are influenced by various factors. However, most of the literatures studied the pollution characteristics in a steady state. Analyzing the indoor particulate matter from the perspective of a dynamic state is more beneficial to understand the pollution characteristics of indoor particulate matter and put forward specific measures to improve the indoor air quality.

This paper takes an office in north China as the research object. Outdoor infiltration experiment and correlation experiment are conducted. The experiment measures the changes of mass concentration and particle number concentration of indoor particulate matter in various conditions. Then, the pollution characteristics and dynamic changes of indoor particulate matter under different particulate concentrations are studied. The maximum increase values, the maximum increase rates, and the penetration factors are calculated and compared. Finally, the correlation between indoor particulate matter and outdoor particulate matter is studied.

\section{Materials and Methods}

2.1. Air Infiltration Experiment. The experimental subject is an office on the third floor in a university office building in Baoding.

The office building is $100 \mathrm{~m}$ away from the trunk road in urban areas. The area of the office is $38.8 \mathrm{~m}^{2}(7.6 \mathrm{~m} \times 5.1 \mathrm{~m})$, the door is $1.8 \mathrm{~m}^{2}(0.9 \mathrm{~m} \times 2.0 \mathrm{~m})$, and the window is $4.2 \mathrm{~m}^{2}$ $(1.2 \mathrm{~m} \times 0.87 \mathrm{~m} \times 4)$; the floor is covered by the ordinary cement mortar. The landscape of the building is shown in Figure 1(a). The rectangle in Figure 1(a) represents the position of the experiment office, and the layout of the experiment office is shown in Figure 1(b).

According to the diagonal principle, the sampling point in the experiment was set in the center of the room. And it was set at $0.8 \mathrm{~m}$ above the floor level [14]. The intelligent dust detector and laser particle counter were placed on both sides of the sampling point. The experimental instruments are shown in Table 1.

There are three ways for outdoor pollutants to enter the room: air infiltration via gaps of doors and windows, natural ventilation, and personnel entering. This study only considers air infiltration, and the door and windows were closed when the experiment was carried out. Thus, the outdoor pollution source entered the room through air infiltration. The outdoor wind condition is an important factor affecting the air infiltration. To ensure the unity of the experimental conditions, the experiment was conducted in sunny days and the windless or breezy days; that is, the influence of the wind condition on the experiment was neglected.

In the experiment, the mass concentration of PM10 of the outdoor atmosphere was used as the evaluation basis of the outdoor pollution level. The outdoor pollution levels were divided into $200-300,300-400,400-500,500-600$, and $600-700 \mu \mathrm{g} \cdot \mathrm{m}^{-3}$.

As the experiment duration is only two hours and the experiment was conducted in sunny days and the windless or breezy days, the outdoor PM10 mass concentration did not greatly change during the experiment duration (two hours). During the experiment of a certain condition of outdoor PM10 concentration, the outdoor PM10 concentration was also measured, and the outdoor PM10 concentration should be in the specific range; otherwise, the experiment at this condition of outdoor PM10 concentration should be reconducted again.

Before the experiment, the air purifier was used to purify the indoor particulate pollution concentration to a lower level. Then, the influence of outdoor infiltration on indoor particulate matter was studied, respectively.

The experiment time was set as two hours. As the intelligent dust detector requires the experimenter to manually change the cutting head of $1.0 \mu \mathrm{m}, 2.5 \mu \mathrm{m}$, and $10 \mu \mathrm{m}$, the mass concentrations of PM1, PM2.5, and PM10 were measured every five minutes. Meanwhile, the laser particle counter recorded the particle number concentration of particles of $0.3-0.5 \mu \mathrm{m}, 0.5-1.0 \mu \mathrm{m}, 1.0-2.5 \mu \mathrm{m}$, $2.5-5.0 \mu \mathrm{m}, 5.0-10.0 \mu \mathrm{m}$, and more than $10 \mu \mathrm{m}$ every five minutes.

2.2. Correlation Experiment. In order to further study the influence of outdoor infiltration on indoor particulate matter, the outdoor pollution concentration and the indoor pollution concentration were simultaneously measured in different days both in summer and in winter. In the experiment days, the window and door were kept closed for 12 hours. Both indoor and outdoor mass concentrations of PM1, PM2.5, and PM10 were measured by the intelligent dust detector.

One hundred thirty-six sets of data in summer and 75 sets of data in winter were collected.

\section{Results and Discussion}

3.1. Variation Characteristics of Indoor Particulate Matter Concentration. Figures 2-6 show the curves of the indoor particulate matter concentrations changing with time when the outdoor mass concentrations of PM10 were 200-300, $300-400, \quad 400-500, \quad 500-600$, and $600-700 \mu \mathrm{g} \cdot \mathrm{m}^{-3}$, respectively. From the figures, it is shown that the changing trends of the indoor particles in different outdoor pollution levels are similar. The changing trends of the indoor particle concentrations in $200-300$ and $600-700 \mu \mathrm{g} \cdot \mathrm{m}^{-3}$ are selected and analyzed in the paper.

Figure 2(a) shows the curves of the mass concentrations of the indoor particles changing with time when the outdoor mass concentration of PM10 is $200-300 \mu \mathrm{g} \cdot \mathrm{m}^{-3}$. The mass concentration of PM1 steadily increases. At the end of the experiment, its maximum value reaches $172 \mu \mathrm{g} \cdot \mathrm{m}^{-3}$, which is $80 \mu \mathrm{g} \cdot \mathrm{m}^{-3}$ higher than its initial value. The mass concentrations of PM1-2.5 and PM2.5-10 fluctuate with time in a small range. At the end of the experiment, the mass 


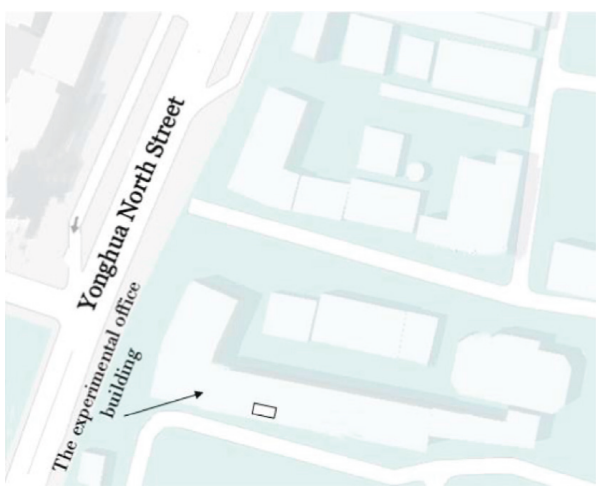

(a)

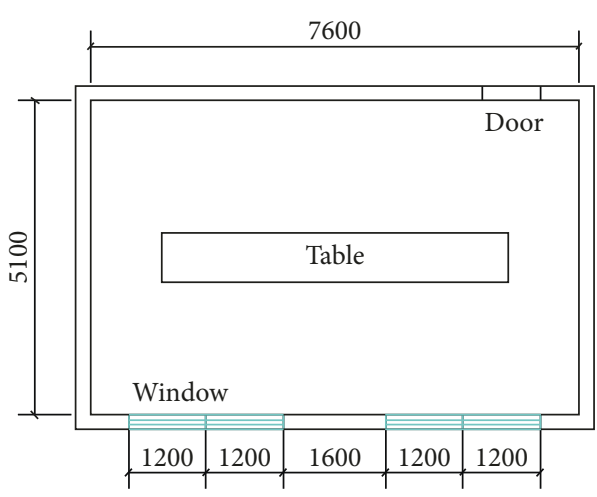

(b)

FIgURE 1: (a) The landscape of the building and (b) the layout of the experiment office.

TABLE 1: Measurement parameters and measuring instruments.

\begin{tabular}{lcccc}
\hline Parameters & Instrument & Model & Range & Accuracy \\
\hline Mass concentration & Intelligent dust detector & DUSTTRAK 8520 & $0.001-100 \mathrm{mg} \cdot \mathrm{m}^{-3}$ & $\pm 0.001 \mathrm{mg} \cdot \mathrm{m}^{-3}$ \\
Number concentration & Laser particle counter & AEROTRAK 8220 & $>0.3 \mu \mathrm{m}$ & $\pm 5 \%$ \\
\hline
\end{tabular}

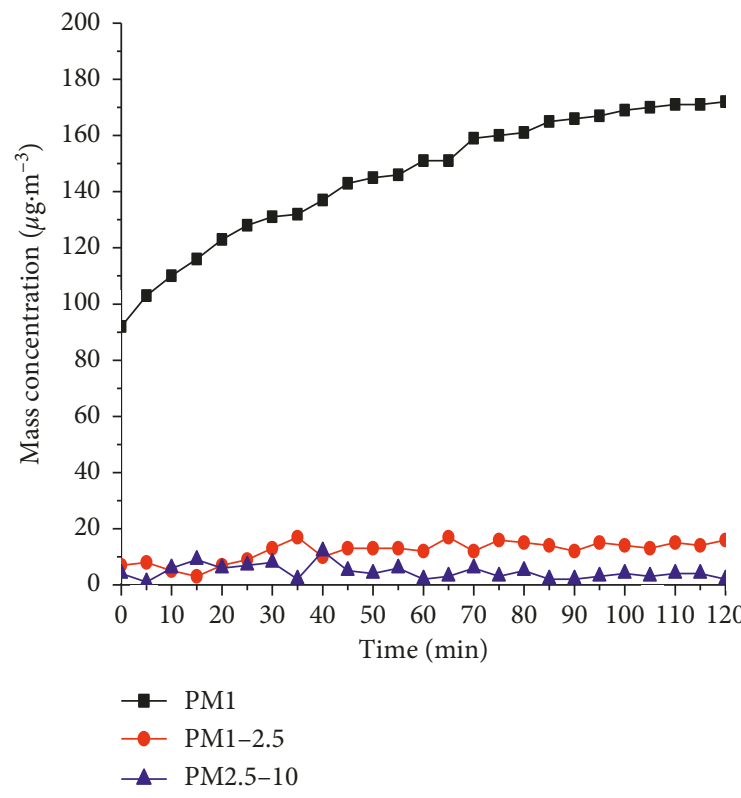

(a)

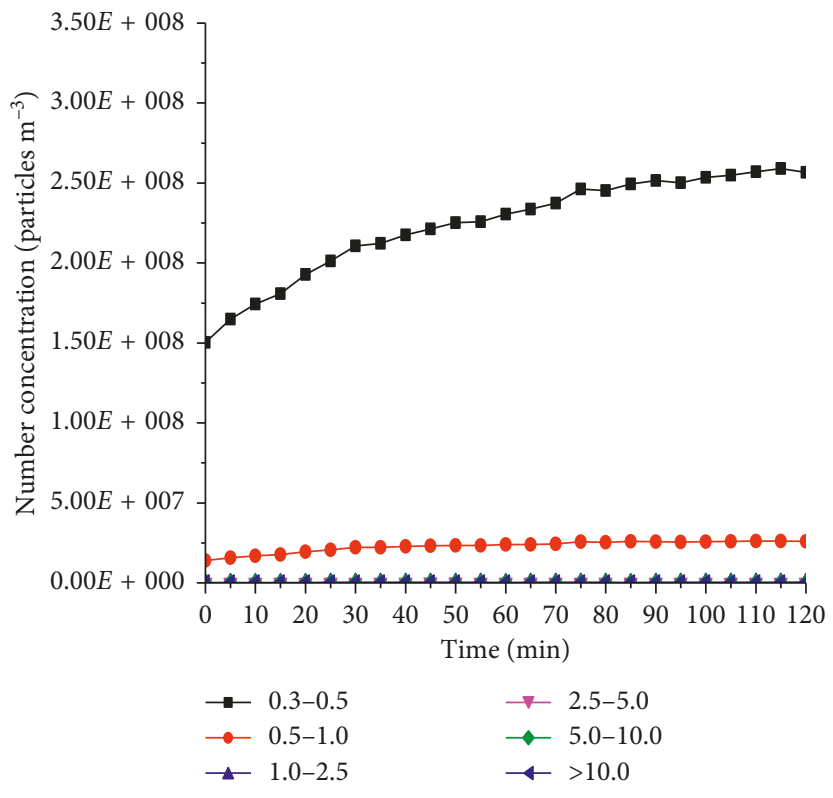

(b)

FIgURE 2: The indoor particle concentration in outdoor PM10 $=200-300 \mu \mathrm{g} \cdot \mathrm{m}^{-3}$ : (a) mass concentration; (b) number concentration.

concentration of PM1-2.5 is $9 \mu \mathrm{g} \cdot \mathrm{m}^{-3}$ higher than its initial value. However, there is no significant increase for the mass concentration of PM2.5-10.

Figure 2(b) shows the curve of the number concentrations of the indoor particles changing with time when the outdoor mass concentration of PM10 is $200-300 \mu \mathrm{g} \cdot \mathrm{m}^{-3}$. The number concentration of the particles in the range of $0.3-0.5 \mu \mathrm{m}$ gently rises. At the end of the experiment, its value increases from $1.5 \times 10^{8}$ particles $\cdot \mathrm{m}^{-3}$ to $2.6 \times 10^{8}$ particles $\cdot \mathrm{m}^{-3}$, which increases by $1.1 \times 10^{8}$ particles $\cdot \mathrm{m}^{-3}$. Further analysis of experimental data shows that the particle number concentrations in the range of $0.5-1.0 \mu \mathrm{m}$, $1.0-2.5 \mu \mathrm{m}$, and $2.5-5.0 \mu \mathrm{m}$ all show a small increase. At the end of the experiment, their values are $1.2 \times 10^{7}, 1.5 \times$ $10^{5}$, and $8.5 \times 10^{3}$ particles $\cdot \mathrm{m}^{-3}$ higher than their initial values, respectively. The number concentrations in the 


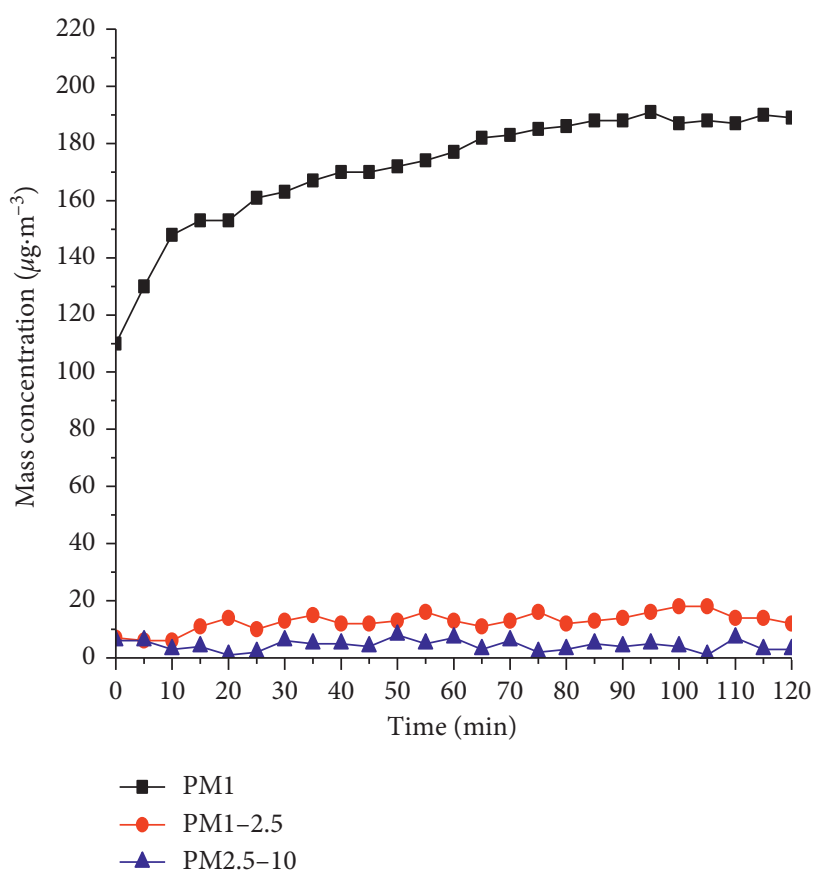

(a)

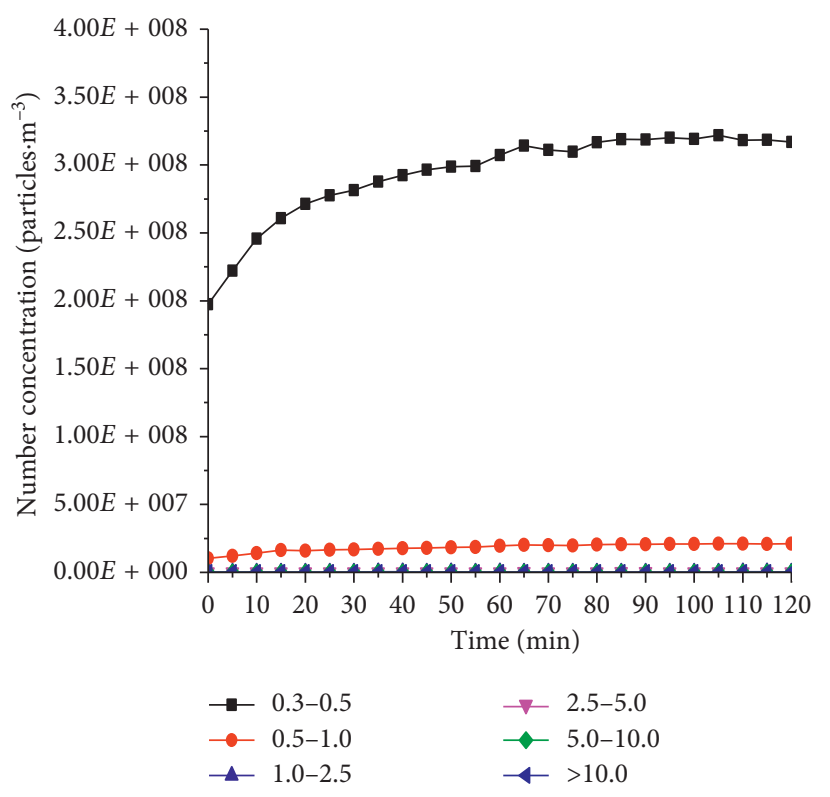

(b)

FIgURE 3: The indoor particle concentration in outdoor PM10 $=300-400 \mu \mathrm{g} \cdot \mathrm{m}^{-3}$ : (a) mass concentration; (b) number concentration.

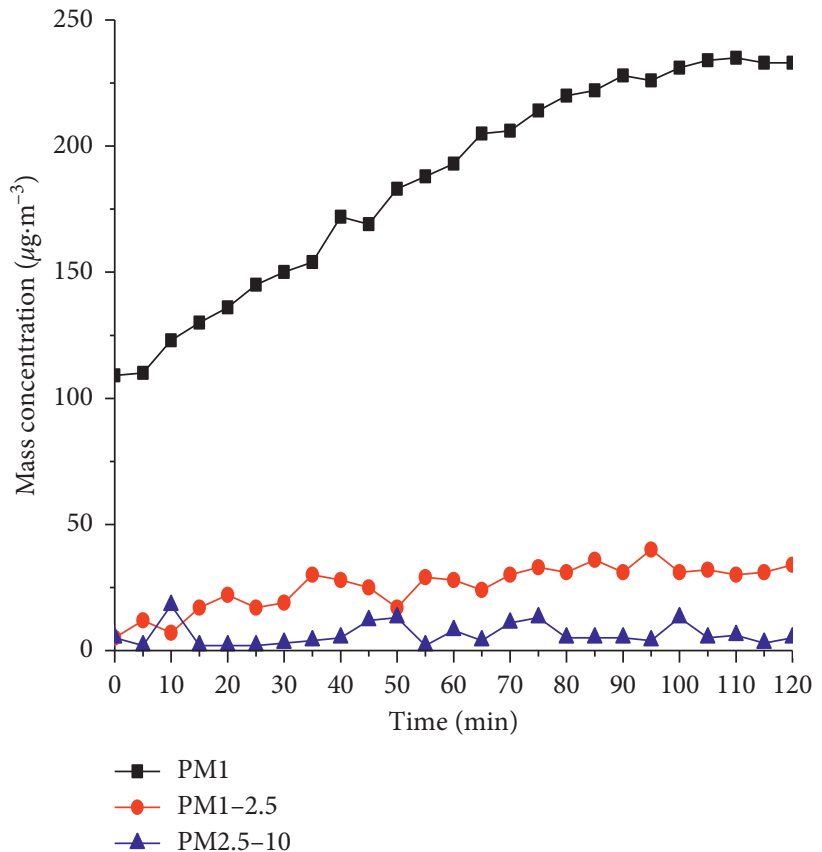

(a)

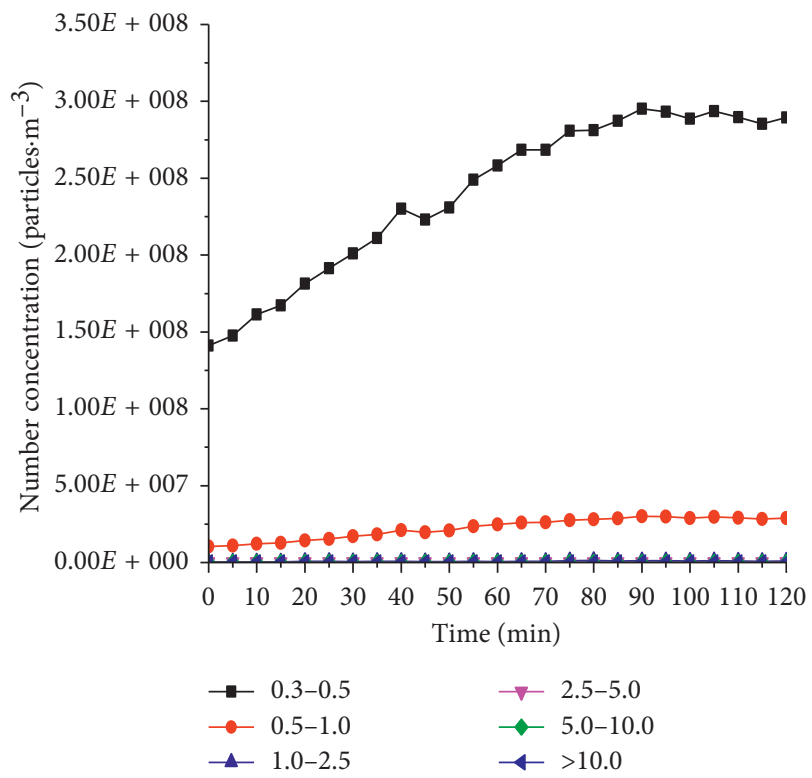

(b)

FIGURE 4: The indoor particle concentration in outdoor PM10 $=400-500 \mu \mathrm{g} \cdot \mathrm{m}^{-3}$ : (a) mass concentration; (b) number concentration.

range of $5.0-10.0 \mu \mathrm{m}$ and larger than $10 \mu \mathrm{m}$ slightly decrease. At the end of the experiment, their values are $6.0 \times$ $10^{3}$ and $3.2 \times 10^{3}$ particles $\cdot \mathrm{m}^{-3}$ lower than their initial values. This may be due to the increase of particles in other size crowds out the space of larger particles. It can be seen that the effect of outdoor infiltration on the number concentration of particles in the range of $0.3-0.5 \mu \mathrm{m}$ is the most significant.

Figure 6(a) shows the curves of the mass concentrations of the indoor particles changing with time when the outdoor mass concentration of PM10 is $600-700 \mu \mathrm{g} \cdot \mathrm{m}^{-3}$. The mass concentration of PM1 steadily increases from the initial 


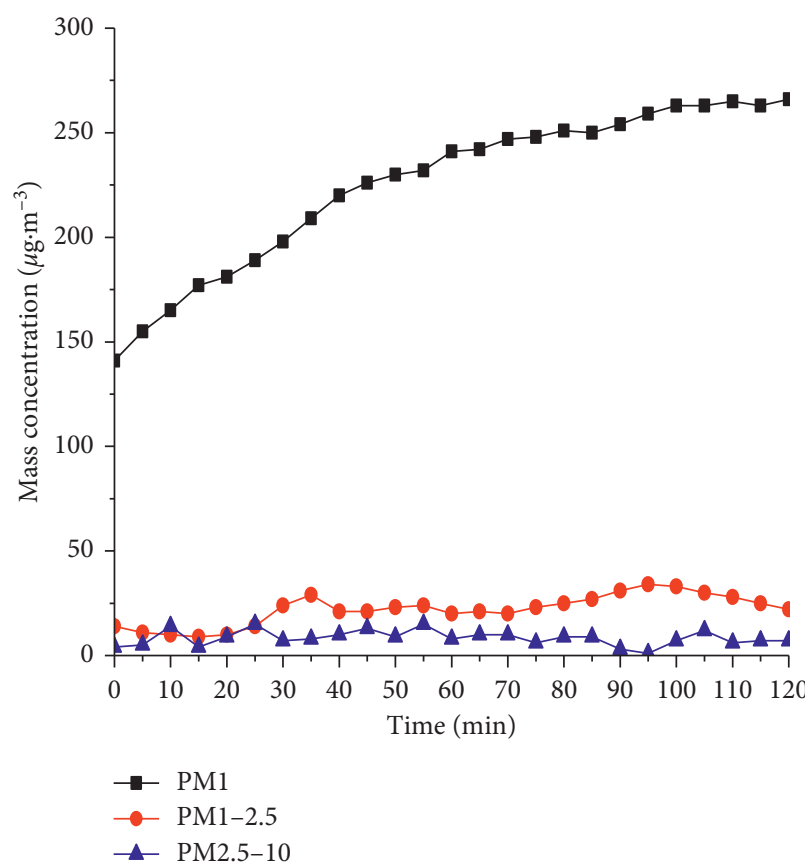

(a)

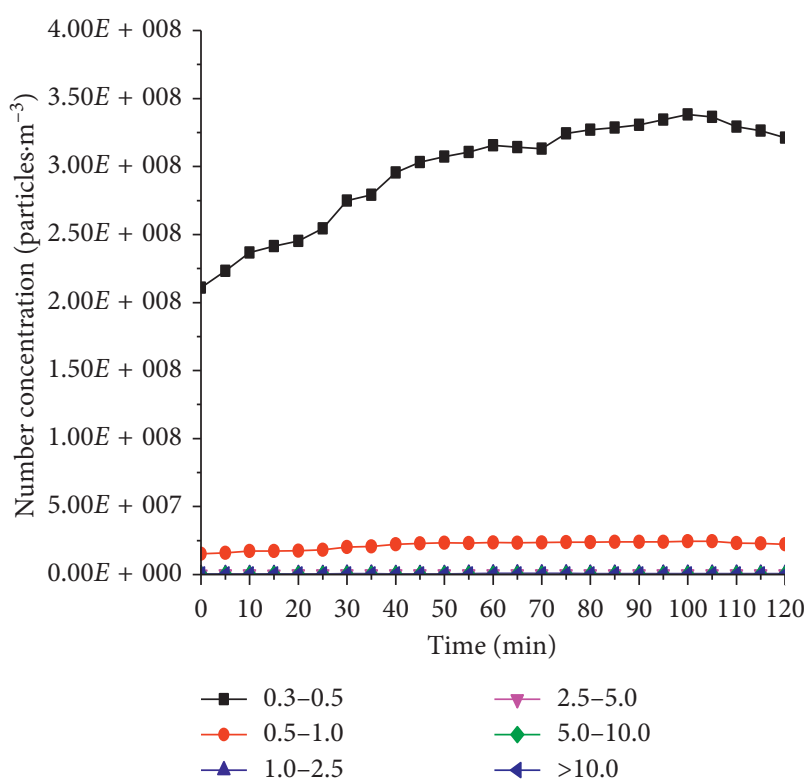

(b)

FIGURE 5: The indoor particle concentration in outdoor PM10 $=500-600 \mu \mathrm{g} \cdot \mathrm{m}^{-3}$ : (a) mass concentration; (b) number concentration.

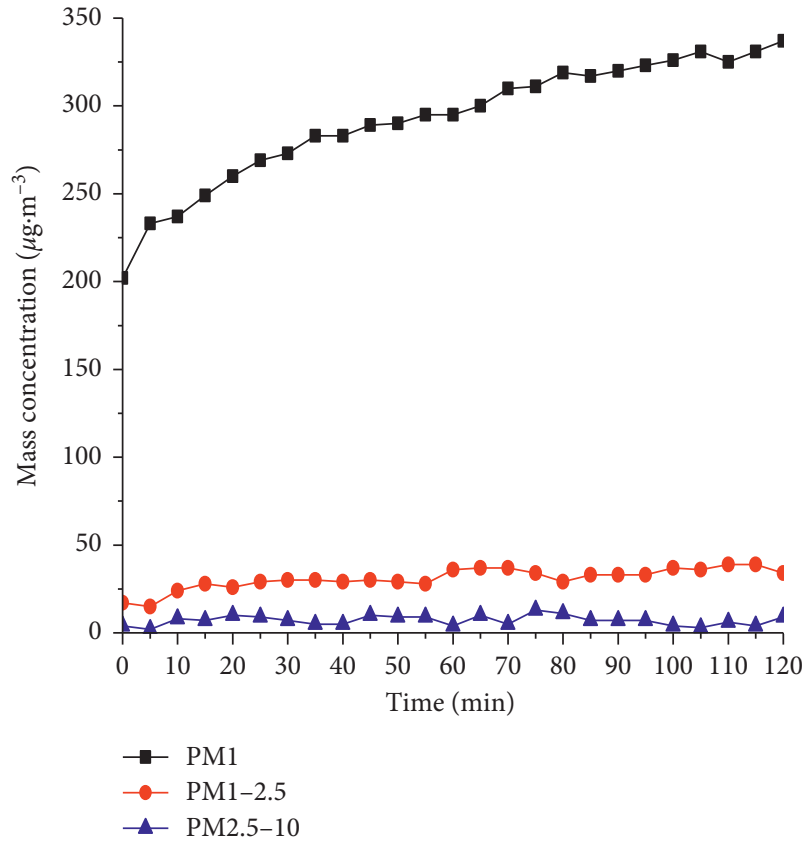

(a)

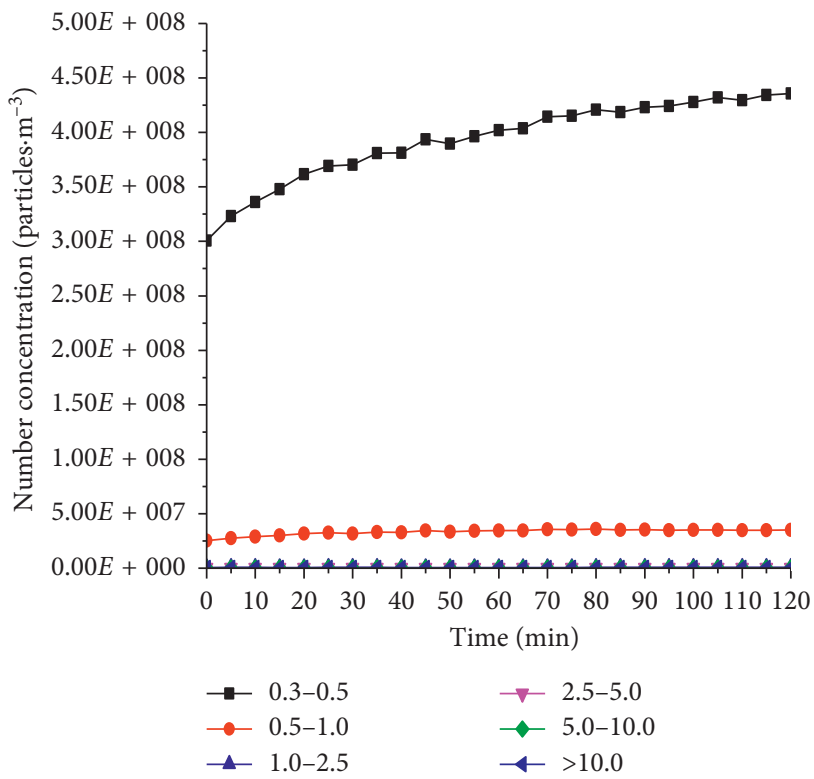

(b)

FIGURE 6: The indoor particle concentration in outdoor PM10 $=600-700 \mu \mathrm{g} \cdot \mathrm{m}^{-3}$ : (a) mass concentration; (b) number concentration.

value $202 \mu \mathrm{g} \cdot \mathrm{m}^{-3}$ to $337 \mu \mathrm{g} \cdot \mathrm{m}^{-3}$ (increases by $135 \mu \mathrm{g} \cdot \mathrm{m}^{-3}$ ). The mass concentrations of PM1-2.5 increase slowly. At the end of the experiment, its value increases from the initial value $17 \mu \mathrm{g} \cdot \mathrm{m}^{-3}$ to $34 \mu \mathrm{g} \cdot \mathrm{m}^{-3}$. The mass concentration of PM2.5-10 fluctuates in a small range without an obvious increase.
Figure 6(b) shows the curve of the number concentrations of the indoor particles changing with time when the outdoor mass concentration of PM10 is $600-700 \mu \mathrm{g} \cdot \mathrm{m}^{-3}$. The number concentration of particles in the range of $0.3-0.5 \mu \mathrm{m}$ increases slowly, and its value increases from the initial value of $3.0 \times 10^{8}$ particles $\cdot \mathrm{m}^{-3}$ to $4.4 \times 10^{8}$ particles 
$\mathrm{m}^{-3}$, which increases by $1.4 \times 10^{8}$ particles $\mathrm{m}^{-3}$. At the end of the experiment, the number concentration of particles in the range of $0.5-1.0 \mu \mathrm{m}$ increases from the initial value of $2.5 \times$ $10^{7}$ particles $\cdot \mathrm{m}^{-3}$ to $3.5 \times 10^{7}$ particles $\cdot \mathrm{m}^{-3}$, which increases by $1.0 \times 10^{7}$ particles $\cdot \mathrm{m}^{-3}$. The number concentrations of particles in the range of $1.0-2.5 \mu \mathrm{m}, 2.5-5.0 \mu \mathrm{m}, 5.0-10.0 \mu \mathrm{m}$, and larger than $10.0 \mu \mathrm{m}$ do not significantly change with time.

\subsection{Effects of Outdoor Source Penetration on the Indoor} Particulate Matter Concentration. In order to further compare the influence of outdoor pollution level on the indoor concentrations of different particle sizes, the maximum increase values and maximum increase rates of the mass concentrations of different particle sizes in different outdoor pollution levels are analyzed. The results are shown in Table 2.

As shown in Table 2, the penetration of outdoor particulate matter has significant influences on indoor concentration without indoor pollution sources. For PM1, the higher the concentration of outdoor particulate matter is, the greater the increase value of the indoor concentration is. However, for PM1-2.5 and PM2.5-10, the maximum increase values fluctuate. It indicates that the outdoor pollution level do not significantly affect the indoor concentrations of PM1-2.5 and PM2.5-10.

The penetration of suspended particles in the atmosphere to the building envelope is usually expressed by the penetration factor $P$, which is defined as the ratio of concentration before and after penetration through the building envelope [15]. Table 3 compares the penetration factors of particles in different particle sizes at different outdoor particle concentrations. It can be seen that the penetration factor of particles in each particle size does not gradually increase with the increase of the outdoor particle concentration. This is mainly because of the different physical characteristics of particles in different outdoor concentrations. In addition, it can be seen from Table 3 that even though the door and the windows are closed, the penetration factors of $0.3-1.0 \mu \mathrm{m}$ particles are greater than 0.5 , and the penetration factors of $0.3-0.5 \mu \mathrm{m}$ particles are greater than 0.6 .

\subsection{Relationships of the Indoor and Outdoor Particulate} Matter under Outdoor Infiltration. Based on the 136 sets of data in summer and 75 sets of data in winter obtained from the correlation experiment, the influence of outdoor infiltration on indoor particulate matter is further analyzed.

Figures 7(a) and 7(b) show the relationships between the mass concentrations of indoor PM1 and outdoor PM1 in summer and winter, respectively. According to linear regression on the indoor and outdoor data, the relationships between indoor and outdoor mass concentrations of PM1 in summer and winter are linear fitted by Origin8.5, respectively:
Summer:

$$
C_{\text {in }}=21.44+0.56796 C_{\text {out }}(r=0.71) .
$$

Winter:

$$
C_{\text {in }}=26.67+0.65842 C_{\text {out }}(r=0.66),
$$

where $C_{\text {in }}$ is the indoor particulate matter concentration $\left(\mu \mathrm{g} \cdot \mathrm{m}^{-3}\right)$ and $C_{\text {out }}$ is the outdoor particulate matter concentration $\left(\mu \mathrm{g} \cdot \mathrm{m}^{-3}\right)$.

Figures $8(\mathrm{a})$ and $8(\mathrm{~b})$ show the relationships between the mass concentrations of indoor PM2.5 and outdoor PM2.5 in summer and winter, respectively. The relationships between indoor and outdoor PM2.5 concentrations in summer and winter are obtained as follows:

Summer:

$$
C_{\text {in }}=21.16+0.54072 C_{\text {out }}(r=0.74) .
$$

Winter:

$$
C_{\text {in }}=26.73+0.72884 C_{\text {out }}(r=0.72) .
$$

Figures 9 (a) and 9(b) show the relationships between the mass concentrations of indoor PM10 and outdoor PM10 in summer and winter, respectively. And the relationships between indoor and outdoor PM10 concentrations in summer and winter are obtained.

Summer:

$$
C_{\text {in }}=25.24+0.51969 C_{\text {out }}(r=0.73) .
$$

Winter:

$$
C_{\text {in }}=22.90+0.75315 C_{\text {out }}(r=0.74) .
$$

As the experiment was conducted in sunny days and the windless or breezy days, Equations (1)-(6) can be only applied in the conditions of sunny days and the windless or breezy days. However, similar equations can be obtained by the above methods.

From Equations (1)-(6), it can be seen that, in summer, the indoor PM1 is more affected by the outdoor particle concentration; in winter, the indoor PM10 is more affected by the outdoor particle concentration. In addition, indoor particulate matter is more affected by outdoor particulate matter in winter.

To sum up, the outdoor infiltration has the most significant effect on the indoor PM1 concentration. The penetration factors of $0.3-0.5 \mu \mathrm{m}$ particle are greater than 0.6 , and its penetration is the most obvious. The pollution sources of outdoor particulate matter are various, and many heavy metals and bacteria are attached on the particles, which cause great harm to human health. Therefore, the tightness of building envelopes, doors, and windows should be paid enough attention. For new buildings, doors and windows must be designed and installed according to the specifications. Especially in some heavily polluted areas, double doors and windows can be used. 
TABLE 2: The variation of particles in different sizes under different conditions.

\begin{tabular}{|c|c|c|c|c|c|c|}
\hline \multirow{2}{*}{$\begin{array}{l}\text { Outdoor } \\
\text { concentration } \\
\left(\mu \mathrm{g} \cdot \mathrm{m}^{-3}\right)\end{array}$} & \multicolumn{2}{|c|}{ PM1 } & \multicolumn{2}{|c|}{ PM1-2.5 } & \multicolumn{2}{|c|}{ PM2.5-10 } \\
\hline & $\begin{array}{l}\text { Maximum increase } \\
\text { value }\left(\mu \mathrm{g} \cdot \mathrm{m}^{-3}\right)\end{array}$ & $\begin{array}{c}\text { Maximum } \\
\text { increase rate (\%) }\end{array}$ & $\begin{array}{l}\text { Maximum increase } \\
\text { value }\left(\mu \mathrm{g} \cdot \mathrm{m}^{-3}\right)\end{array}$ & $\begin{array}{c}\text { Maximum } \\
\text { increase rate (\%) }\end{array}$ & $\begin{array}{l}\text { Maximum increase } \\
\text { value }\left(\mu \mathrm{g} \cdot \mathrm{m}^{-3}\right)\end{array}$ & $\begin{array}{c}\text { Maximum } \\
\text { increase rate (\%) }\end{array}$ \\
\hline $200-300$ & 80 & 87.0 & 10 & 142.9 & 8 & 200.0 \\
\hline $300-400$ & 81 & 73.6 & 11 & 157.1 & 1 & 16.7 \\
\hline $400-500$ & 126 & 115.6 & 35 & 700 & 13 & 260.0 \\
\hline $500-600$ & 125 & 88.7 & 20 & 142.9 & 11 & 275.0 \\
\hline $600-700$ & 135 & 66.8 & 22 & 129.4 & 9 & 225.0 \\
\hline
\end{tabular}

TABle 3: Penetration factor of particles with different particle sizes under each outdoor condition.

\begin{tabular}{|c|c|c|c|c|c|c|}
\hline \multirow{2}{*}{ Outdoor concentration $\left(\mu \mathrm{g} \cdot \mathrm{m}^{-3}\right)$} & \multicolumn{6}{|c|}{ Penetration factor, $P$} \\
\hline & $0.3-0.5 \mu \mathrm{m}$ & $0.5-1 \mu \mathrm{m}$ & $1-2.5 \mu \mathrm{m}$ & $2.5-5 \mu \mathrm{m}$ & $5-10 \mu \mathrm{m}$ & $>10 \mu \mathrm{m}$ \\
\hline $200-300$ & 0.889 & 0.807 & 0.376 & 0.326 & 0.200 & 0.068 \\
\hline $300-400$ & 0.920 & 0.716 & 0.503 & 0.282 & 0.158 & 0.149 \\
\hline $400-500$ & 0.613 & 0.515 & 0.483 & 0.272 & 0.132 & 0.071 \\
\hline $500-600$ & 0.744 & 0.571 & 0.524 & 0.425 & 0.287 & 0.165 \\
\hline $600-700$ & 0.780 & 0.627 & 0.506 & 0.406 & 0.302 & 0.288 \\
\hline
\end{tabular}

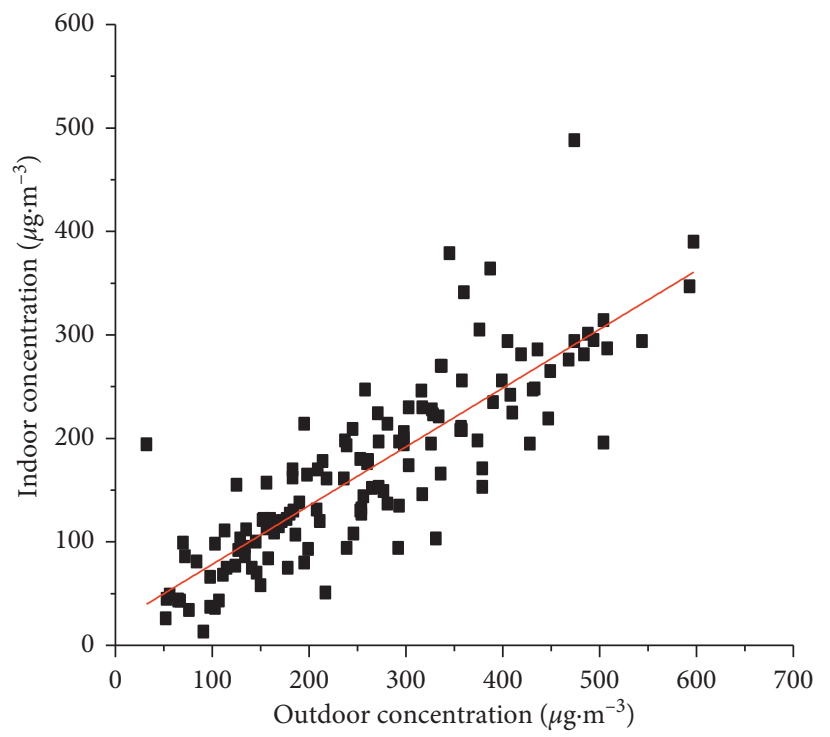

(a)

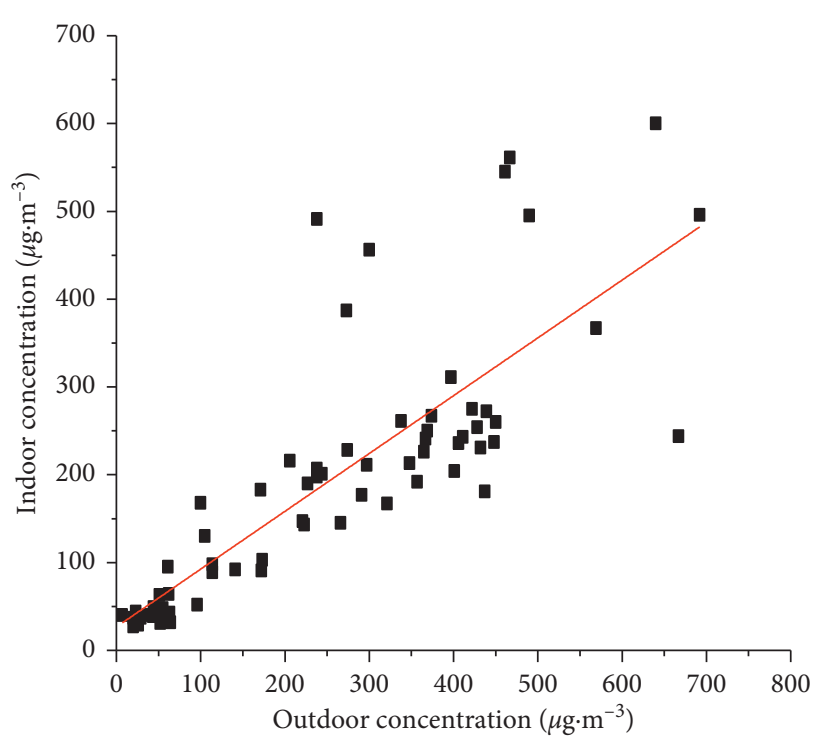

(b)

FIGURE 7: The relationships between the indoor PM1 concentrations and the outdoor PM1 concentrations: (a) summer; (b) winter.

\section{Conclusion}

This study takes an office as the research object. Air infiltration experiment and correction experiment are carried out. Firstly, the variation characteristics of mass concentration and number concentration of indoor particles under five outdoor pollution levels are analyzed. Secondly, the maximum increase values and the maximum increase rates of the mass concentrations with different sizes are analyzed. Furthermore, the penetration factors of the particulate matter in different particle sizes are compared. Finally, the correlation between indoor and outdoor particulate matter concentration is studied in summer and winter. This paper can provide a basis for proposing measures to improve indoor air quality. Specifically, the following conclusions are obtained:

(1) The effect of outdoor infiltration on indoor particulate matter concentration is significant. And the greater the outdoor particle concentration is, the greater the impact on indoor particulate matter is. The outdoor infiltration has the most significant effect on the indoor PM1 concentration. The mass concentrations of PM1-2.5 and PM2.5-10 fluctuate with time in a small range, and there is no obvious increase. 


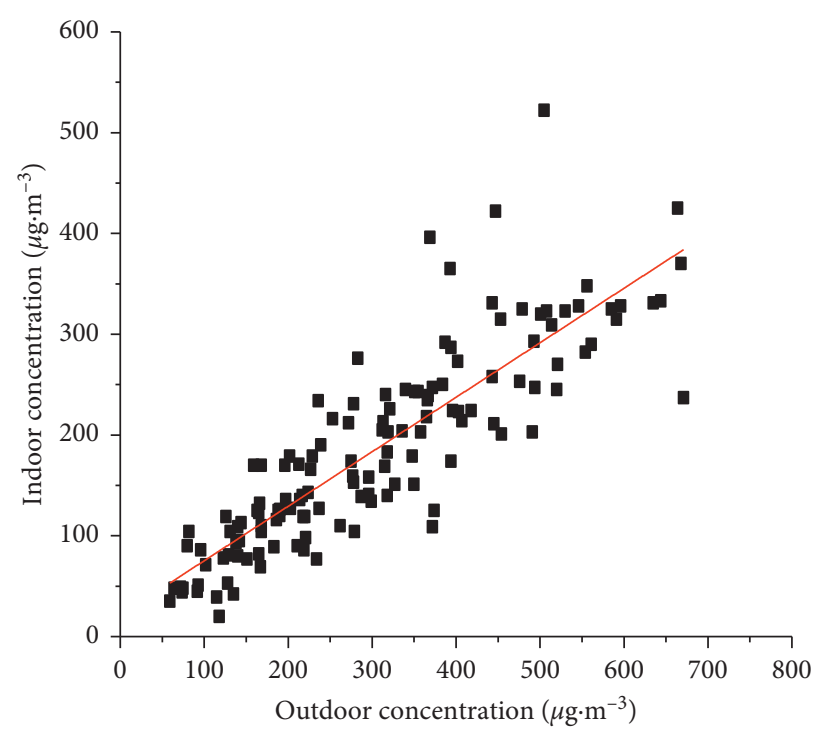

(a)

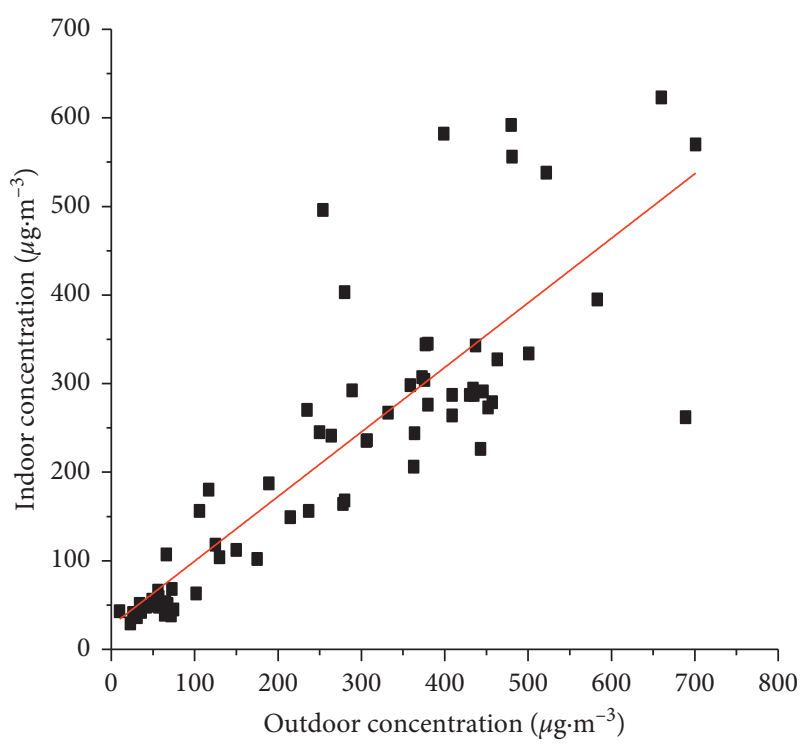

(b)

FIgURE 8: The relationships between the indoor PM2.5 concentrations and the outdoor PM2.5 concentrations: (a) summer; (b) winter.

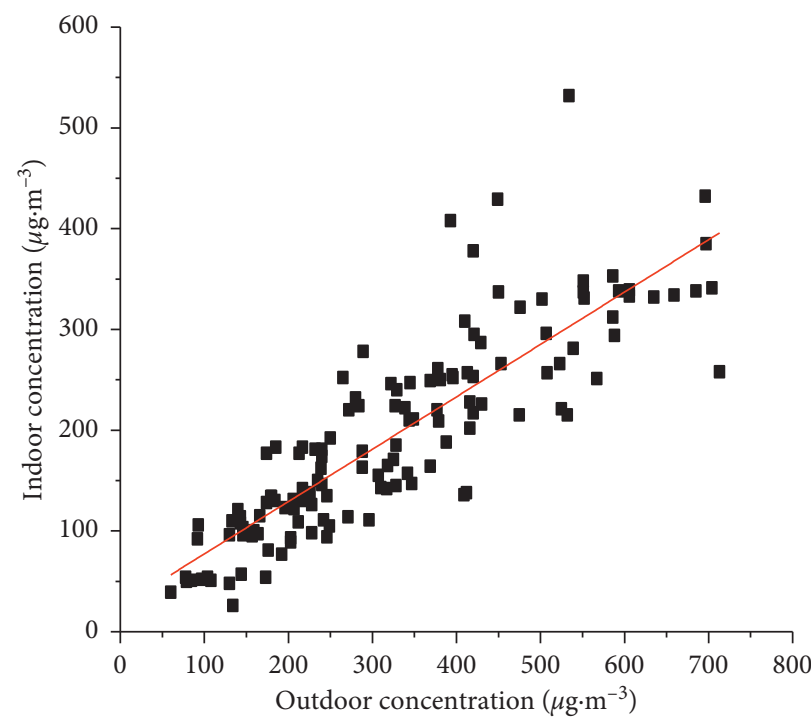

(a)

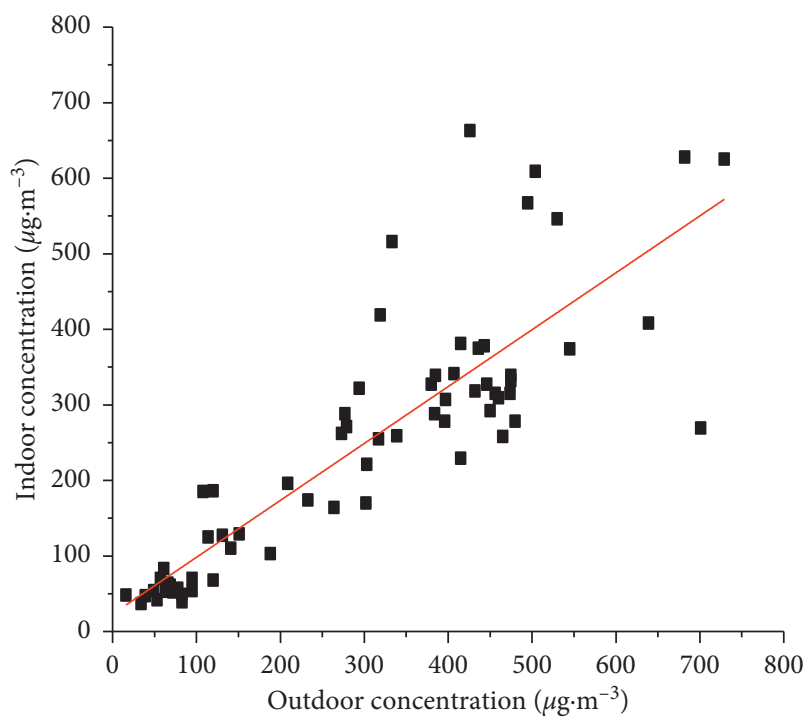

(b)

Figure 9: The relationships between the indoor PM10 concentrations and the outdoor PM10 concentrations: (a) summer; (b) winter.

(2) Due to different physical characteristics of particulate matter under different outdoor concentrations, the penetration factor of particles in each particle size does not increase with the increase of outdoor particle concentration. The penetration factors of $0.3-1.0 \mu \mathrm{m}$ particles are greater than 0.5 , and the penetration factors of $0.3-0.5 \mu \mathrm{m}$ particles are greater than 0.6.

(3) The mass concentration of indoor PM1 is more affected by the outdoor particulate matter in summer. The mass concentration of PM10 is more affected by the outdoor particulate matter in winter.
Moreover, indoor particulate matter is more affected by outdoor particulate matter in winter.

(4) The tightness of building envelopes, doors, and windows should be paid enough attention. Especially in some heavily polluted areas, double doors and windows can be used.

\section{Data Availability}

The data used to support the findings of this study are available from the corresponding author upon request. 


\section{Conflicts of Interest}

The authors declare that there are no conflicts of interest.

\section{Acknowledgments}

This research has been supported by the Fundamental Research Funds for the Central Universities (Grant no. 2018MS110) and the Natural Science Foundation of Hebei Province (Grant No. E2016502035).

\section{References}

[1] J. N. Wang, S. R. Cao, Z. Li, Y. Zhang, and S. M. Li, "Human exposure to carbon monoxide and inhalable particulate in Beijing, China," Biomedical and Environmental Sciences, vol. 1, no. 1, pp. 5-12, 1998.

[2] H. L. Huang, M. Q. Lee, and H. W. Shih, "Assessment of indoor bioaerosols in public spaces by real-time measured airborne particles," Aerosol and Air Quality Research, vol. 17, no. 9, pp. 2276-2288, 2017.

[3] Y. F. Wang, "Measurement of air quality during a decorating engineering," Aerosol and Air Quality Research, vol. 14, no. 7, pp. 2029-2039, 2014.

[4] D. Saraga, T. Maggos, E. Sadoun et al., "Chemical characterization of indoor and outdoor particulate matter (PM 2.5, PM 10) in Doha, Qatar," Aerosol and Air Quality Research, vol. 17, no. 5, pp. 1156-1168, 2017.

[5] M. W. Lin, L. Y. Chen, and Y. K. Chuah, "Investigation of a potted plant (Hedera helix) with photo-regulation to remove volatile formaldehyde for improving indoor air quality," Aerosol and Air Quality Research, vol. 17, no. 10, pp. 25432554, 2017.

[6] Q. P. Xu, J. Z. Wang, J. Q. Liu, and S. C. Peng, "Particulate size distribution and sources evaluation of $n$-alkanes during longterm haze episode around Chaohu Lake, Eastern China," Aerosol and Air Quality Research, vol. 17, no. 8, pp. 1975-1984, 2017.

[7] N. Jiang, Z. Dong, Y. Xu et al., "Characterization of PM10 and PM2.5 source profiles of fugitive dust in Zhengzhou, China," Aerosol and Air Quality Research, vol. 18, no. 2, pp. 314-329, 2018.

[8] Y. You and Z. P. Bai, "Research advances in exposure to ambient particulate matter and health effects," Asian Journal of Ecotoxicology, vol. 7, no. 2, pp. 123-132, 2012.

[9] J. Crawford, D. D. Cohen, A. D. Griffiths, S. D. Chambers, A. G. Williams, and E. Stelcer, "Impact of atmospheric flow conditions on fine aerosols in Sydney, Australia," Aerosol and Air Quality Research, vol. 17, no. 7, pp. 1746-1759, 2017.

[10] S. E. Hamdan, K. Limam, M. O. Abadie, and A. Bendoua, "Deposition of fine particles on building internal surfaces," Atmospheric Environment, vol. 42, no. 39, pp. 8893-8901, 2008.

[11] M. Li, C. Wu, and W. Pan, "Sedimentation behavior of indoor airborne microparticles," Journal of China University of Mining and Technology, vol. 18, no. 4, pp. 588-593, 2008.

[12] M. L. Pereira, G. Graudenz, A. Tribess, and L. Morawska, "Determination of particle concentration in the breathing zone for four different types of office ventilation systems," Building and Environment, vol. 44, no. 5, pp. 904-911, 2009.

[13] J. Schwartz, D. W. Dockery, and L. M. Neas, "Is daily mortality associated specifically with fine particles," Journal of the Air and Waste Management Association, vol. 46, no. 10, pp. 927-939, 1996.

[14] GB/T18883-2002, Indoor Air Quality Standard, China Standards Press, Beijing, China, 2002.

[15] F. Zhang, Numerical Simulation of Suspended Particulate Matter Penetration through Building Envelope, Hunan University, Changsha, China, 2007. 


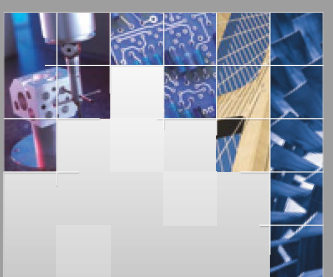

\section{Enfincering}
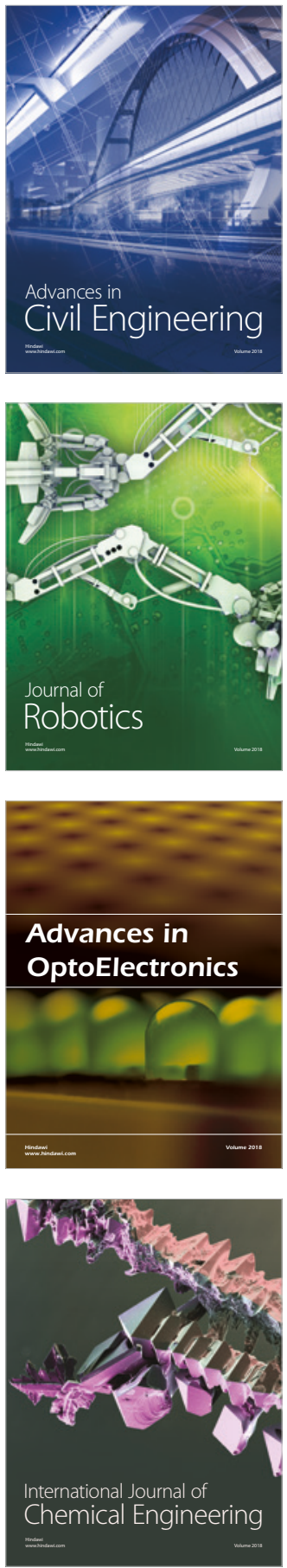

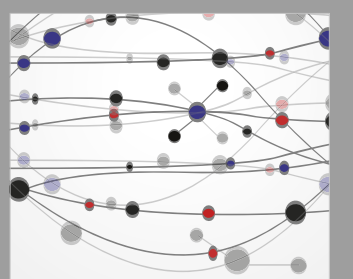

\section{Rotating \\ Machinery}

The Scientific World Journal

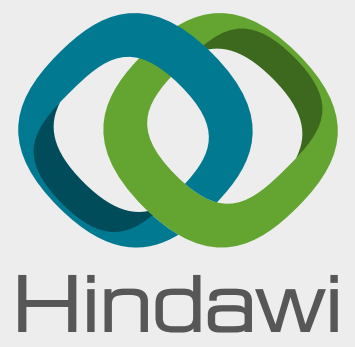

Submit your manuscripts at

www.hindawi.com
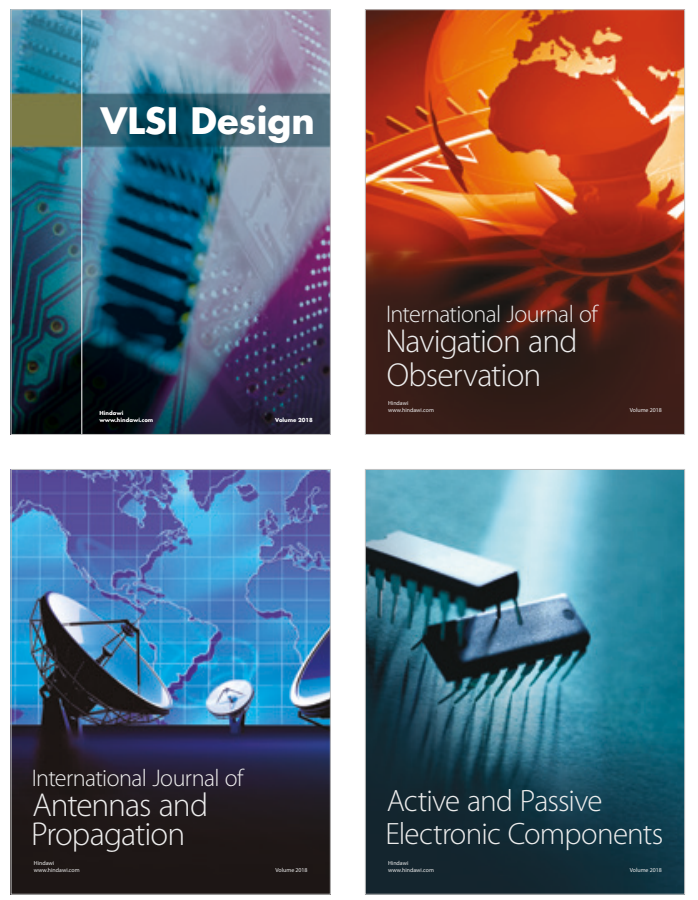
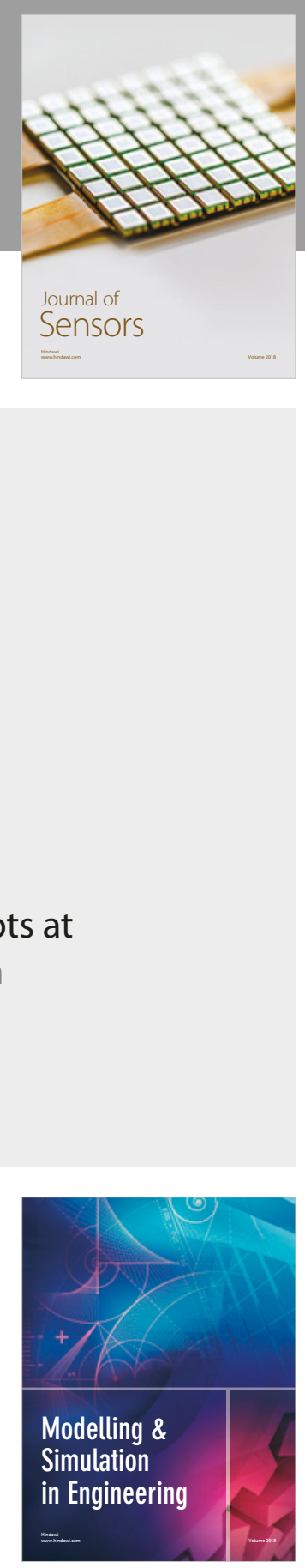

\section{Advances \\ Multimedia}
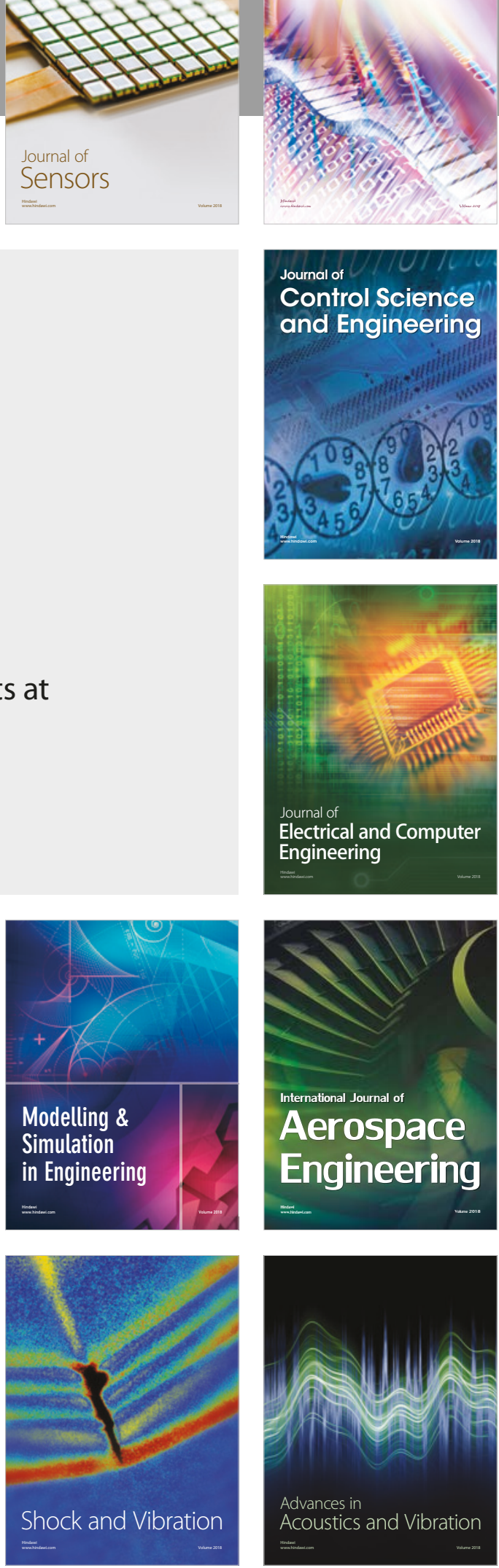